\title{
ШАФИИТСКАЯ ШКОЛА В ИСЛАМСКОМ ПРАВЕ
}

\begin{abstract}
Аннотация: Предметом исследования автора статьи является шафиитская правовая школа, которая, как известно, оформилась в рамках классического суннизма в период раннего средневековья. Шафиизм-вторая после ханафизма по степени влиятельности и уровню популярности школа в исламском праве. Значение данного учения в прочессе эволючии мусульманской системы правосудия было настолько велико, что «следы» шафиизма в той или иной степени можно проследить и в законодательстве некоторых стран современного Востока. В период раннего средневековья шафиизм проник и на территорию современной России. В статье исследуется творческий путь основателя шафиитской правовой школы-известного мыслителя раннего средневековья аш-Шафии (767-820 гг.), анализируются его воззрения в области действующей системы правосудия. Особое внимание уделяется вопросу источников права, апеллирование $\kappa$ которым разрешалось в рамках шафиизма. Это объясняется тем, что именно классификация источников права и методы их применения определяли повестку дня юридической науки в данный отрезок времени. В данной статье автором впервые в российском правоведении достаточно подробно рассматривается подход шафиитов к проблеме источников права. В исследовании дан анализ тех особенностей, которые были присущи шафиитской правовой школе при апеллировании как к основным, так и к вспомогательным источникам. Помимо этого автором акцентируется внимание на компромиссном характере шафиизма, который оперируя исключительно научныли методами, сумел синтезировать наиболее перспективные положения более «либерального» ханафизма и консервативного маликизма. Особенно подчеркивается важность изучения шафиитской правовой школь отечественными спеииалистами, в виду того, что данное учение достаточно широко представлено в традициях и обычаях некоторых российских народов.
\end{abstract}

Abstract: The subject of research is the Shafi'i law school, which is known to be formed in the framework of classical Sunni Islam in the early medieval period. By the level of influence and popularity in the Islamic school of law, Shafiizm is second after Hanafizm. The value of this doctrine in the evolution of Islamic justice system was so great that in varying degrees, Shafiizm can be traced in the laws of some countries of the modern East. In the early medieval period, Shafiizm penetrated the territory of modern Russia. The paper investigates the creative path of the founder of Shafi'i law school - a famous thinker of the early Middle Ages ash-Shafi'i (767-820); his views are analyzed in the current system of justice. Particular attention is paid to the sources of law, the appeal to which was allowed within Shafiizm. This is explained by the fact that this classification of sources of law and their methods determines the agenda of legal science in a given time. In this article, for the first time in Russian jurisprudence, the author considers the Shafi'ites approach to the problem of the sources of law in sufficient detail. The study analyzes the features that were inherent to Shafi'i school of law when appealing to both the main and auxiliary sources. Besides, the author focuses on the compromise nature of Shafiizm, which managed to synthesize the most promising provisions of more "liberal" Hanafizm and conservative Malikizm using scientific methods. The importance of domestic experts studying Shafi'i law school is particularly emphasized due to the fact that this doctrine is sufficiently represented in the traditions and practices of some Russian peoples.

Ключевые слова: шафиизм, аль-Шафии, правовая школа, Арабский халифат, источник права, Коран, Сунна, суждения сподвижников, решение по усмотрению, территория распространения

Keywords: Shafiizm, al-Shafi'i, legal school, the Arab Caliphate, source of law, the Koran, the Sunnah, judgments of companions, decision at the discretion, area of application.

рамках исламского суннизма в эпоху раннего средневековья, как известно, зародился целый ряд правовых школ, отличающихся между собой в первую очередь подходами к основным и вспомогательным источникам права. Только четыре из них - ханафитская, маликитская, шафиитская и ханбалитская - выдержав испытание временем, «дожили» до настоящего времени, наложив отпечаток на нормы законодательства стран мусульманского мира. Учитывая, что «более чем в сорока странах ислам яв- 
DOI: $10.7256 / 1811-9018.2014 .2 .10495$

При цитировании этой статьи сноска на dоі обязательна

\section{Право и политика $2(170) \cdot 2014$}

ляется государственной религией и играет весомую роль в международных делах и мировой политике» ${ }^{1}$, изучение основ мусульманского законодательства, которые, в свою очередь, неразрывно связаны с той или иной правовой школой, приобретает в настоящее время особую актуальность. Необходимо добавить, что нередко в юридической литературе данные правовые школы называются мазхабами, что, однако, не совсем верно с точки зрения содержательной наполненности каждого из этого понятий ${ }^{2}$.

Безусловно, шафиитская школа занимает особое место в исламской правовой доктрине. Приверженцы рассматриваемой школы отличались своим стремлением внести в раннесредневековое исламское право характер научности, системности и логической завершенности. Шафииты, рассматривая те или иные аспекты правосудия, нередко обращались к базовым принципам логики, пришедшей на Восток из античной Греции, нередко углублялись в философские рассуждения и умозаключения. Вовлечение основ логики в правовую науку способствовало тому, что разработанные ими положения и нормы права стали более понятны для неспециалистов, что в свою очередь способствовало широкому распространению шафиизма. Как удачно заметил современный известный турецкий исследователь исламского права, профессор Университета Мармара Э. Экинджи, сравнивая основные суннитские правовые школы, «ханафитская концепция рациональна, она, в первую очередь, защищает интересы собственника и индивида; шафиитское направление диалектично и академично; маликиты - известные аристократы, а ханбалиты - еще те консерваторы».

Основатель шафиитской правовой школы - известный мыслитель раннесредневекового исламского Востока аш-Шафии. Он родился в 767 г. в городе Газа, который сегодня является одним из крупнейших городов в Палестинской автономии (администрации). Мыслитель происходил из известного в арабском мире рода Курайшитов. Аш-Шафии потерял отца еще в детском возрасте, и его мать, оставшись без средств к существованию, приняла решение вместе с детьми

\footnotetext{
${ }^{1}$ Быкова Е. В. Современные вопросы ислама. - М.: Юрлитинформ, 2009. - C. 27.

${ }^{2}$ См., например: Момотов В.В., Свечникова Л.Г. Основы исламского законодательства: учеб. пособие. - Краснодар: Кубанский гос. ун-т, 2009. - С. 16.

${ }^{3}$ Ekinci E. İslam hukuku tarihi. - İstanbul: Arı sanat yayınevi, 2006. - C. 80 .
}

перебраться в Мекку. Уже к семи годам будущий известный правовед выучил наизусть Коран, в подростковом возрасте ему удалось освоить некоторые трактаты Малика ибн Ананса (713 - 795 гг.), основателя маликитской правовой школы. В пятнадцать лет юный аш-Шафии уже давал советы горожанам по тем или иным вопросам фикха, то есть базовых процессуальных норм исламского законодательства. Слава о его способностях дошла и до городской знати, и наместник Мекки отправил молодого человека изучать право к Малику ибн Анасу в Медину. Известно, что авторитетный в империи наставник, который преподавал правоведческие дисциплины аш-Шафии в течении девяти лет, благословил своего ученика и предрек ему блестящее будущее.

После кончины великого учителя аш-Шафии на некоторое время обосновался в Йемене, где с помощью судьи данного региона устроился на работу в местных органах власти. Известно, что в результате конфликта войск халифа с шиитами аш-Шафии случайно попал в плен. Халиф, поняв абсурдность обвинений в адрес суннитского правоведа, помиловал его и оказал материальную поддержку.

Желая постигнуть азы родного арабского языка ашШафии вскоре покинул «цивилизацию», перебравшись в пекло Аравийской пустыни, где кочевали сохранившие древние традиции арабские племена.

Известно, что в 809 г, находясь в Мекке, и в 817 г., будучи в Багдаде, Аш-Шафии плотно общался с основателем ханбалитской правовой школы Ахмадом ибн Ханбалем (780 - 855 гг).

В период с 807 по 815 гг. основатель шафиизма жил и работал в Багдаде, в центре средневековой арабской культуры и науки, после чего перебрался в Египет, где и скончался в 820 г. Великий мыслитель прошлого похоронен в Каире. В настоящее время его гробницу посещают многочисленные паломники.

Необходимо добавить, что значительную часть своей зрелой жизни аш-Шафии провел, путешествуя по различным регионам Арабского халифата, общаясь с известными в стране правоведами, философами, богословами. Отличительной чертой мыслителя явилось то, что он обладал академическим складом ума, всегда стремился к познаниям, увлекался многими научными дисциплинами, достигшими своего рассвета в эпоху раннего средневековья на Ближнем Востоке. Данное обстоятельство отразилось на формировании и дальнейшем развитии той правовой школы, основы которой аш-Шафии заложил. Как говорилось выше, шафиитская правовая школа характеризуется исследователями как сугубо академическая, тесно связанная 
с логикой, философией и даже лингвистикой. Данное учение наименее идеологизировано. Шафииты, образно говоря, всегда старались держаться на расстоянии от политики. Как уже говорилось выше, познания ашШафии не ограничивались правоведением: мыслитель прекрасно знал арабскую и персидскую литературу, увлекался математикой, логикой, философией. У него были свои взгляды на обсуждаемые в данный отрезок времени научные проблемы. Например, мыслитель считал совершенно излишними и неактуальными для исламской философии дискуссии среди почитателей калама о соотношении судьбы и воли. Примерно в таком же ракурсе он отрицал какой-либо смысл в спорах представителей ханафитской и маликитской правовых школ о соотношении хадисов, из которых, как известно, состоит Сунна, с так называемым вольнылм толкованиeм, о котором речь пойдет ниже.

К плеяде известных российскому научному сообществу приверженцев шафиизма обычно причисляют теоретика государственного права аль-Маварди (974 1058 гг.), создателя калама (суннитской философской школы) аль-Ашари (873 - 935 гг.), выдающегося философа аль-Газали (1058 - 1111 гг.), специалиста права ac-Суйути (1445 - 1505 гг.), крупнейшего иранского историка Рашида ад-дин ал-Хамадани (1247 - 1318 гг.) и многих других ${ }^{4}$.

Прежде чем перейти к базовым положениям шафиизма, думается, есть необходимость рассмотреть основные особенности данной правовой школы, которые систематизированы и активно обсуждаются в зарубежном научном сообществе. Одна из основных особенностей шафиизма заключается в том, что ашШафии сумел синтезировать самые важные положения из двух противоборствующих в VIII в. идеологических и правовых направлений - так называемого «западного учения» в лице Медины и Мекки, с одной стороны, и «восточного учения» в лице Багдада и Куфы, с другой стороны. Напомню, что раскол, произошедший между западом и востоком в среде интеллектуалов Арабского халифата произошел в VIII в., и носил в своей сути дихотомичный характер «хадис - вольное толкование». На Западе империи, где традиции той самой политической элиты, которая заложила основы исламской правовой доктрины, были всегда достаточно прочны, насс, то есть совокупность основных положений Священной книги и Сунны, обладал статусом наивысшей сакральности. Данное обстоятельство означало, что правосудие в Арабском халифате должно опираться на два основных

${ }^{4}$ Мамотов В. В., Свечникова Л. Г. Указ. соч. - С.19. источника права, и лишь в исключительных случаях судьям позволялось апеллирование к другим источникам. На Востоке в рассматриваемой отрезок времени были сильны идеи вольнодумства, что сказалось не только на политической мысли и философии, но и на интерпретации основных положений права. Правоведымыслители Востока ввели в оборот понятие вольное толкование (rey), что вызывало неприятие и критику со стороны мединских и мекканских интеллектуалов. Заслуга аш-Шафии состоит именно в том, что ему удалось синтезировать отдельные положения обоих направлений, изложить и аргументировано обосновать свое видение назревшей проблемы, а тмакже найти поддержку по обе стороны конфликта.

Вторая особенность рассматриваемой правовой школы состоит в том, что шафиизм делится на два уровня в зависимости от периода жизни аш-Шафии. Так называемый «старый шафиизм» был концептуализирован и развит мыслителем в багдадский период своей жизни, а «новый» или «поздний шафиизм», который, в общем-то, и считается основой шафиитской доктрины - в годы его жизни в Египте, то есть после 815 г. Считается, что «старый шафиизм» во многом близок маликитской правовой школе. В работе «аль-Мебсут», которую ученый написал еще будучи в Багдаде, отчетливо чувствовалось влияние воззрений Малика ибн Анаса 5 . В этот же период аш-Шафии издал известный фундаментальный труд «Рисала», дощедший в оригинале до наших дней. В российском гуманитарном знании данную книгу иногда именуют «Трактат» ${ }^{6}$. Однако в египетский период воззрения аш-Шафии претерпели значительные изменения, видимо, в силу того, что жизнь мусульманской общины Северной Африки разительно отличалась от реалий Двуречья. Об этом свидетельствует те существенные корректировки, которые были внесены автором в свои труды. Основные положения его работ стали более умеренными, по некоторым позициям приблизившись к основам ханафизма. И все же, как признают российские исследователи: «Шафииты значительно жестче ханафитов и ближе к маликитам с точки зрения строгости и нетерпимости по отношению к спекулятивным, умозрительным построениям» ${ }^{\text {. }}$

В зарубежной научной литературе иногда выделяется и третья важная особенность шафиитской

\footnotetext{
${ }^{5}$ Yaman A., Çalış H. Islam hukukuna giriş. - Istanbul:M.Ü. İlahiyat fakültesi vakfı yayınları, 2012. - C.

${ }^{6}$ См., например: Ханмагомедов Я. М. Сложение мусульманского (суннитского) права // Исламоведение. 2013. № 2. - С.101.

${ }^{7}$ Мамотов В. В., Свечникова Л. Г. Указ. соч. - С.19.
} 
DOI: $10.7256 / 1811-9018.2014 .2 .10495$

При цитировании этой статьи сноска на dоі обязательна

\section{Право и политика $2(170) \cdot 2014$}

правовой школы. Как говорилось выше, для шафиитов была характерна достаточно выраженная теоретизированность в своих взглядах, систематизированность и упорядоченность основных положений выдвигаемой ими концепции правосудия. Данное обстоятельство отчетливо проявилось в их частой апелляции к методу дедукции, возможность и необходимость применения которого в области права ими была обоснована. Именно этим объясняется, например, то, что кияс, нашедший широкое применение в других правовых школах, у шафиитов находится на последнем месте, а апеллирование к нему оговорено многочисленными условиями ${ }^{8}$. Вообще методу дедукции посвятил свои труды известный философ средневекового Востока аль-Газали, также, как уже отмечалось, известный приверженец шафиизма. Более того, как констатируют исследователи данного вопроса, пристальное внимание шафиитов к данному методу был продиктовано и их стремлением «усмирить пыл» своего главного конкурента - ханафитов, которые в свою очередь опирались больше на индуктивные способы правотворчества. Исходя из этого, напрашивается вывод, что шафииты занимали более взвешенную и сдержанную позицию по сравнению со своим основным конкурентом в борьбе за сферу влияния на мусульманском Востоке в эпоху раннего средневековья.

Апелляционная очередность основных и вспомогательных источников права согласно шафиитской концепции права выглядит следующим образом: Священная книга и Сунна, статус которых равнозначен, иджма, так называемые единодушные суждения сподвижников (сахабов), так называемые единичные суждения сподвижников (сахабов), а также кияс 9. Ввиду того, что первые три источника мусульманского права - Коран, Сунна и иджма - достаточно хорошо исследованы российскими правоведами, автор статьи предлагает более подробно остановиться на суждениях сподвижников (сахабов) и киясе.

В российском правоведении суждения сахабов, которыми именовались люди из окружения Мухаммада, в качестве источника права не исследовались. Исключением, пожалуй, является работа известного отечественного специалиста по мусульманскому законодательству В. К. Самигуллина «Ислам и право: опыт постижения», в которой он информирует чи-

\footnotetext{
${ }^{8}$ Более подробно см.: Минниахметов Р. А., Нуриев Б. Д. Государство и право в исламской правовой доктрине. - Уфа: РИЦ БашГУ, 2013. - C. 57.

${ }^{9}$ Более подробно см.: Şener A. İslamda mezhepler ve hukuk ekolleri // Ankara üniversitesi ilahiyat fakültesi degisi. - 1984, № 1. - C. 388.
}

тателя о важности в исламской правовой доктрине мнений соратников Мухаммада. Автор констатирует, что действия и высказывания лиц из окружения Мухаммада образуют самостоятельный источник исламского права ${ }^{10}$. Заслуживает особого внимания вопрос о классификации суждений сахабов. Как показала практика применения рассматриваемого нами источника исламского права, суждения сахабов имели различную степень юридической силы в зависимости от иерархического положения самого источника информации в общине. Изречения так называемых праведных халифов считались неоспоримыми и не подлежащими ревизии. К умозаключениям сахабов более низкого статуса отношение было более осторожным. Более того, вопрос о том, какую юридическую силу имели суждения сахабов, решался по-разному в различных правовых школах. Так, например, мыслители-правоведы из числа ханафитов делили данный источник права на три уровня. Наибольшую силу, как уже говорилось, имели суждения четырех праведных халифов. Причина их высокого статуса кроется в том, что комментарии к положениям Сунны были даны еще при жизни Мухаммада. Ханафиты называют эти комментарии «пророческими». На более низкой ступени находились трактователи Сунны и норм исламского права, которые стали интерпретировать правовые нормы после кончины Мухаммада. И к последней группе относились многочисленные сахабы, известные своими редкими и фрагментарными высказываниями. К их суждениям община обращалась в исключительных случаях. У шафиитов отношение к действиям и высказываниям сподвижников было более благосклонное. Мало того, что их статус в шафиитской правовой школе была выше кияса, так и сами суждения сахабов разделялись всего на две группы: «единодушные», то есть не вызывающие сомнений и споров в общине изречения, и «единичные», то есть редко встречаемые и транслируемые высказывания.

Достаточно интересна позиция шафиитов и относительно кияса. По мнению представителей рассматриваемой правовой школы, кияс завершает тот перечень источников права, которые могут быть задействованы в ходе судебных разбирательств. В основе данной позиции лежал их тезис о том, что любое дело обязательно найдет свое решение в рамках уже наработанной источниковой базы. Решение, как показывает практика, по всей вероятности вытекает из положений двух основных и равно-

\footnotetext{
${ }^{10}$ См.: Самигуллин В. К. Ислам и право: опыт постижения. - Уфа: Гилем, 2006. - С.92.
} 
DOI: $10.7256 / 1811-9018.2014 .2 .10495$

При цитировании этой статьи сноска на dоі обязательна

Правовая и политическая мысль

правных источников исламского права - Священной книги и Сунны. В случае невозможности вынесения вердикта, что уже маловероятно, используются остальные источники права вплоть до кияса, который по своей сути универсален, то есть применяем в любом случае, ибо наработанная практика этому не препятствует. Данное свойство универсальности (kıyasu'l-ille) придает исламскому правосудию качество завершенности и самодостаточности. Более того, как считали шафииты, «благодаря киясу законодательство Арабского халифата приобретало в итоге и свойство систематизированности и унифицированности (kıyasu'ş-şebeh), что только способствовало принятию справедливого решения по каждому рассматриваемому судебному делу» ${ }^{11}$.

Итак, исходя из вышеперечисленных источников исламского права можно сделать следующие немаловажные выводы, которые в некоторой степени могут прояснить непростую ситуацию, сложившуюся в сообществе мыслителей-правоведов на Ближнем Востоке в эпоху раннего средневековья.

Во-первых, аш-Шафии и его последователи не видели принципиальной разницы между Священной книгой и Сунной и считали оба источника права равнозначными. С данным утверждением согласны многие российские исследователи. Замечу, что ни одна из правовых школ на Ближнем Востоке в эпоху средневековья ни поддержала данное положение шафиитов.

Во-вторых, шафииты достаточно высоко оценивали значимость иджмы, что также подвергалось большой критике со стороны шиитских и ханбалитских мыслителей-правоведов.

В-третьих, согласно основным положениям шафиитской правовой школы, статус суждений сахабов был выше значимости кияса.

И, в-четвертых, необходимо добавить, что ашШафии отказался от апеллирования к такому важному источнику исламского права, как решение по усмотрению, который нередко именуют в отечественном правоведении истихсан ${ }^{12}$. Данный источник относится к группе вспомогательных источников в мусульманском законодательстве и нашел широкое применение в доктрине ханафитов. Известно, что аш-Шафии в своем известном труде о методологии исламского права «Рисала», который упоминался выше, посвятил целую главу критике данного источника права. И, как справедливо признают отечественные исследователи, «ханафитский истихсан шафииты не признают, по их мнению, если ис- тихсан будет позволен, то это может открыть дорогу для неограниченного применения субъективного мнения» ${ }^{13}$.

Необходимо добавить, что источник права $p e-$ шение по усмотрению(истихсан) не следует путать с вольным толкованием (рей), о котором также речь также шла выше. Вольное толкование специалистами рассматривается как принцип конструирования теории права в VIII в. в восточной части Арабского халифата. Данное понятие значительно шире по своей содержательности и включает в себя все элементы сложившейся в то время структуры правосудия. Добавлю, что приверженцы шафиитской правовой школы также отвергали и развитый маликитами другой источник права из группы вспомогательных - так называемый истислах, который представляет собой «признание возможности изменения некоторых хадисов Сунны, если их содержание оказалось в противоречии с тем, что признано благом» ${ }^{14}$.

В настоящее время общая численность приверженцев шафиизма в исламском мире достаточно большая: они занимают второе место, уступая первенство лишь ханафитам. Считается, что шафиизм в той или иной степени повлиял на современное законодательство некоторых стран Ближнего Востока, отдельные его «отголоски» прослеживаются в праве Египта и стран Восточной Африки, немало последователей шафиизма в юго-восточной Азии, прежде всего в Индонезии и Малайзии. В российском исламском мире шафиизм сохранился в культуре и традициях некоторых народов Северного Кавказа. В целом, из основных четырех правовых школ, оформившихся в рамках суннитского ислама, шафиитское направление отличается относительной умеренностью в своих базовых положениях, исторически сложившимся прагматизмом, неприятием фанатичной консервативности и безразличием к экспансионизму.

\section{Библиография:}

1. Быкова Е. В. Современные вопросы ислама. - М.: Юрлитинформ, 2009.

2. Момотов В.В., Свечникова Л.Г. Основы исламского законодательства: учеб. пособие. - Краснодар: Кубанский гос. ун-т, 2009.

3. Минниахметов Р. А., Нуриев Б. Д. Государство и право в исламской правовой доктрине. - Уфа: РИЦ БашГУ, 2013.

\footnotetext{
${ }^{11}$ Yaman A., Çalış H. Указ. соч. - C.124.

${ }^{12}$ Ханмагомедов Я. М. Указ. соч. - С.101.
} 
DOI: $10.7256 / 1811-9018.2014 .2 .10495$

При цитировании этой статьи сноска на dоі обязательна

\section{Право и политика $2(170) \cdot 2014$}

4. Самигуллин В. К. Ислам и право: опыт постижения. - Уфа: Гилем, 2006.

5. Ханмагомедов Я. М. Сложение мусульманского (суннитского) права // Исламоведение. 2013. № 2. C. $96-103$.

6. Е. Н. Тамразова — Роль религии и права в становлении Арабского халифата//Политика и общество, № 5, 2012.

7. Ekinci E. İslam hukuku tarihi. - İstanbul: Arı sanat yayınevi, 2006.

8. Yaman A., Çalış H. Islam hukukuna giriş. Istanbul:M.Ü. İlahiyat fakültesi vakfı yayınları, 2012.

9. Şener A. İslamda mezhepler ve hukuk ekolleri // Ankara üniversitesi ilahiyat fakültesi degisi. - 1984, № 1.

10. П. Н. Вишневский Международные финансовые сделки в мусульманском праве // Международное право и международные организации. -2012. -2. - С. 76 - 85.

\section{References (transliteration):}

1. Bykova E. V. Sovremennye voprosy islama. - M.: Yurlitinform, 2009.
2. Momotov V.V., Svechnikova L.G. Osnovy islamskogo zakonodatel'stva: ucheb. posobie. - Krasnodar: Kubanskii gos. un-t, 2009.

3. Minniakhmetov R. A., Nuriev B. D. Gosudarstvo i pravo $\mathrm{v}$ islamskoi pravovoi doktrine. - Ufa: RITs BashGU, 2013.

4. Samigullin V. K. Islam i pravo: opyt postizheniya. Ufa: Gilem, 2006.

5. Khanmagomedov Ya. M. Slozhenie musul'manskogo (sunnitskogo) prava // Islamovedenie. 2013. № 2. S. $96-103$.

6. E. N. Tamrazova - Rol' religii i prava v stanovlenii Arabskogo khalifata//Politika i obshchestvo, № 5, 2012.

7. Ekinci E. İslam hukuku tarihi. - İstanbul: Arı sanat yayınevi, 2006.

8. Yaman A., Çalış H. Islam hukukuna giriş. Istanbul:M.Ü. İlahiyat fakültesi vakfı yayınları, 2012.

9. Şener A. İslamda mezhepler ve hukuk ekolleri // Ankara üniversitesi ilahiyat fakültesi degisi. - 1984, № 1 .

10. P. N. Vishnevskii Mezhdunarodnye finansovye sdelki v musul'manskom prave // Mezhdunarodnoe pravo i mezhdunarodnye organizatsii. - 2012. -2. - C. 76-85. 